Preface

\title{
Etiology of Epilepsy
}

\author{
Philip Smith, MD, FRCP, FAcadMEd ${ }^{1}$ Rhys Thomas, BSc, MRCP, MSc, PhD ${ }^{1}$ \\ 1 The Alan Richens Epilepsy Unit, Department of Neurology, University \\ Hospital of Wales, Cardiff, United Kingdom
}

Semin Neurol 2015;35:191-192.

Epilepsy is such a fascinating and enigmatic condition to study. Not only are seizures common on a population basis, they commonly feature among a range of structural, metabolic, and inflammatory disorders. An attempt to understand the etiology of the epilepsies underpins the 2010 International League Against Epilepsy (ILAE) classification and yet there are many incongruities that mean our current knowledge about the causes of epilepsy can be apparently contradictory. This review is therefore very timely, featuring a cavalcade of great thinkers and writers. It was important for us to recruit clinicians who could tackle the full complexity of these themes and yet describe them in an articulate fashion.

Some of these themes are nonintuitive: For example, it appears that the rarer the epilepsy syndrome, the more likely we are to understand its etiology. Rare devastating epilepsies often form part of a broader disease phenotype, such as in a metabolic condition; however, it is the importance of de novo mutagenesis-in genes that do not normally tolerate variation-that has really expanded the field. The immune basis of certain epilepsies is currently so established that it is possible now to start someone on immunosuppressive therapy even without identifying a specific autoantibody. The risk of seizures following traumatic brain injury remains above the population rate for many years following the apparent resolution of the injury. The identification of a recurrent de novo mutation in KCNC1 makes us think again about the genetic architecture underpinning the progressive myoclonic epilepsies. And the more we understand about the common epilepsies, the more surprises they throw up. For the genetic generalized epilepsies, it is their genomic deletions and duplications in the form of copy number variation; for the focal epilepsies it has been the rise of Mendelian mutations in single genes such as DEPDC5 and GRIN2A. Finally, we are reminded that there is much more to tumorassociated seizures than lesion clearance alone and that the patient factors and pathophysiology must each be taken into account.

Our wish is that when this themed Rhys Thomas, BSc, MRCP, MSc, PhD edition is revised in 10 years or so, that not only have these authors made great strides in understanding "idiopathic" epilepsies better, but that there is a growing field of treatments made possible in light of this information. The results of uncontrolled and pragmatic trials of sirolimus for Pretzel syndrome or quinidine for KCNT1 encephalopathy are tantalizing glimpses into what that 2025 themed edition of Seminars in Neurology might look like.

It was a real pleasure working with such a talented group of authors and we are grateful that they have shared their insights. We know that you will enjoy reading their chapters on the etiology of epilepsy.
Address for correspondence Philip Smith, MD, FRCP, FAcadMEd, The Alan Richens Epilepsy Unit, Department of Neurology, University Hospital of Wales, Heath Park, Cardiff CF14 4XW, United Kingdom (e-mail: SmithPE@cardiff.ac.uk).
Issue Theme Etiology of Epilepsy; Guest Editors: Philip Smith, MD, FRCP, FAcadMEd, and Rhys Thomas, BSc, MRCP, MSc, PhD
Copyright $\odot 2015$ by Thieme Medical Publishers, Inc., 333 Seventh Avenue, New York, NY 10001, USA. Tel: +1(212) 584-4662.
DOI http://dx.doi.org/ 10.1055/s-0035-1552626. ISSN 0271-8235. 